\title{
STRATEGI PERPUSTAKAAN PERGURUAN TINGGI DALAM MENINGKATKAN MINAT BACA SEBAGAI UPAYA MENGANTISIPASI HOAX (STUDI KASUS DI PERPUSTAKAAN UNIVERSITAS SEBELAS MARET SURAKARTA)
}

\author{
Sri Utari \\ UPT Perpustakaan Universitas Sebelas Maret Surakarta \\ Program Magister Ilmu Perpustakaan dan Informasi, UIN Sunan Kalijaga Yogyakarta \\ Korespondensi: sriutarirudhianto@gmail.com
}

Diajukan: 28-05-2018; Direview: 10-09-2018; Diterima: 25-11-2018; Direvisi: 28-11-2018

\begin{abstract}
This paper discusses how the role of university libraries in increasing reading interest as an effort to anticipates hoax with case studies at Sebelas Maret University Library. The aim of the study is to determine the library strategies in increasing reading interest as an effort to combat hoaxes. This study uses qualitative methods with data collection participatory observation and documentation. The conclusion of this study is the strategy adopted by the Sebelas Maret Univercity Library in increasing reading interest is by holding various talk show activities, book fairs, writing seminars and workshops, information literacy, receiving student visits and students, applying excellent and superior services, providing various kinds library collections, and promotions and improvement of library infrastructure facilities. These various efforts are expected that the public's interest in reading will increase so that the public will not easily accept hoax information.
\end{abstract}

\begin{abstract}
ABSTRAK
Artikel ini membahas tentang bagaimana peran perpustakaan perguruan tinggi dalam meningkatkan minat baca sebagai upaya mengantisipasi hoax dengan studi kasus di Perpustakaan UNS. Tujuan penelitian adalah untuk mengetahui strategi perpustakaan dalam meningkatkan minat baca sebagai upaya memerangi hoax. Penelitian ini menggunakan metode kualitatif dengan pengumpulan data observasi parsipatif dan dokumentasi. Kesimpulan penelitian ini adalah strategi yang ditempuh Perpustakaan UNS dalam meningkatkan minat baca adalah dengan menyelenggarakan berbagai kegiatan talk show, pameran buku, seminar dan workshop penulisan, literasi informasi, menerima kunjungan siswa dan mahasiswa, menerapkan layanan prima dan unggul, penyediaan aneka macam koleksi, dan promosi perpustakaan dan peningkatan sarana prasarana perpustakaan. Upaya tersebut diharapkan minat baca masyarakat meningkat sehingga mereka tidak akan mudah menerima informasi hoax.
\end{abstract}

Keywords: Library strategy; Hoax; Fake news; Reading interest; Information literacy; Academic library

\section{PENDAHULUAN}

Teknologi informasi telah berhasil mempopulerkan internet untuk masyarakat. Hasil survei Asosiasi pengguna Jasa Internet Indonesia (APJII) terkait pengguna internet Indonesia tahun 2017 menunjukkan bahwa dari total 262 juta orang diketahui ada 143,26 juta orang $(54,68 \%)$ pengguna internet, jumlah tersebut meningkat dari tahun sebelumnya yaitu 132,7 juta orang. Komposisi berdasarkan usia didominasi pengguna dengan usia 19-34 tahun sebesar 49,52\%; usia 35-54 tahun sebesar 29,55\%; usia 13-18 tahun sebesar 16,68\%; dan usia lebih dari 54 tahun sebesar 4,24\%. Layanan akses internet peringkat tertinggi adalah chatting sebesar $89,35 \%$ dan sosial media sebesar $87,13 \%$. 
Data di atas menunjukkan bahwa internet telah menjadi kebutuhan masyarakat. Pemanfaatan internet ini akan mengubah perilaku masyarakat dalam melakukan pencarian informasi. Fuad dkk. (2017), mengatakan bahwa perilaku pencarian informasi generasi saat ini (generasi Z) yaitu memperoleh informasi secara instan. Mereka tidak memiliki banyak waktu untuk mengevaluasi informasi, baik dari segi relevansi, akurasi, dan sumber berita.

Adanya teknologi informasi dan komunikasi (TIK) yang semakin memudahkan dalam memperoleh informasi, termasuk melalui media sosial. Media sosial memberikan berbagai kemudahan, diantaranya sebagai media promosi, ajang memperbanyak teman, media komunikasi, dan tempat berbagi foto, informasi. Selain memberikan manfaat, media sosial juga mempunyai efek negatif diantaranya menggangu kegiatan belajar, bahaya kejahatan, bahaya penipuan, menggangu kehidupan dan komunikasi keluarga (Putri, dkk, 2016). Munculnya kejahatan melalui media sosial ini, salah satunya disebabkan oleh informasi bohong atau hoax.

Penyebaran informasi hoax bertujuan untuk menipu masyarakat. Menurut Respati (Kompas, 23 Januari 2017), secara psikologis, seseorang dapat dengan mudah menerima informasi hoax karena informasi yang disampaikan sesuai dengan opini atau sikap yang dimiliki, dan terbatasnya pengetahuan yang dimiliki oleh penerima berita. Rendahnya pengetahuan seseorang dan karakter generasi saat ini, yang cenderung ingin memperoleh informasi secara instan tanpa adanya klarifikasi informasi. Berbeda dengan koleksi yang dimiliki oleh perpustakaan, seperti buku, artikel ilmiah, makalah, media masa, dokumen pemerintah, laporan penelitian (skripsi, tesis, disertasi), dokumen produk hukum, dan dokumen pemerintah, yang merupakan informasi terpercaya untuk bahan rujukan (Suyono $\mathrm{dkk}, 2015)$.

Salah satu penyebab masyarakat kurang menyukai untuk menggunakan koleksi perpustakaan adalah rendahnya minat baca. Hasil survei UNESCO tahun 2011 menunjukkan bahwa budaya baca di indonesia berada di tingkat paling rendah dengan nilai 0,001 , artinya setiap 1000 penduduk hanya terdapat 1 orang yang memiliki minat baca (Triatma, 2006). Oleh karena itu, perlu adanya upaya pemerintah dan masyarakat untuk meningkatkan minat baca. Menurut Undang-Undang No.43 Tahun 2007, pasal 48 ayat 1, kegemaran membaca dapat dilakukan melalui keluarga, satuan pendidikan, dan masyarakat. Kemudian, pada pasal 51 menyebutkan tentang kewajiban perpustakaan untuk mendukung dan memasyarakatkan gerakan nasional gemar membaca melalui penyediaan karya tulis, karya cetak, dan karya rekam.

Melihat penetrasi pengguna internet yang mayoritas diminati oleh kalangan usia muda, perpustakaan perguruan tinggi juga dapat berperan aktif dalam meningkatkan minat baca masyarakat. Unit Pelaksana Teknis Perpustakaan Universitas Sebelas Maret (Perpustakaan UNS) sebagai salah satu perpustakaan perguruan tinggi, berperan serta dalam meningkatkan minat baca masyarakat. Upaya tersebut dilakukan untuk menjadikan masyarakat yang memiliki pengetahuan yang tinggi tidak mudah dibohongi oleh informasi/berita bohong. Artikel ini membahas tentang strategi Perpustakaan UNS dalam meningkatkan minat baca dan memerangi informasi hoax.

\section{TINJAUAN PUSTAKA}

\subsection{Perpustakaan Perguruan Tinggi}

Perpustakaan perguruan tinggi merupakan perpustakaan yang tergabung dalam lingkungan lembaga pendidikan tinggi, baik berupa perpustakaan universitas, perpustakaan 
fakultas, perpustakaan akademik, maupun perpustakaan sekolah tinggi (Pamuntjak, 2000). Perpustakaan perguruan tinggi berfungsi sebagai penunjang dan pendukung proses pendidikan yang berlangsung di suatu perguruan tinggi, memperlancar dan menyukseskan tri dharma perguruan tinggi, serta meningkatkan kualitas pendidikan dalam rangka menyikapi dan menjawab tantangan perkembangan ilmu pengetahuan dan teknologi yang sangat pesat.

Ada beberapa strategi yang dapat dilakukan oleh pengelola perpustakaan perguruan tinggi untuk meningkatkan minat baca, yaitu: (1) memperbaiki fasilitas dan karakteristik pelayanan perpustakaan (Siregar, 2004); (2) meningkatkan fasilitas ruangan dan kelengkapan koleksi di perpustakaan serta adanya kerja sama yang baik antara pustakawan dengan dosen (Kasiyun, 2005); (3) menyediakan beragam koleksi/karya yang merupakan informasi sehat yang dapat dimanfaatkan untuk meningkatkan kegemaran membaca (Fuad, 2017). Menurut Nashihuddin (2017), pustakawan harus menyediakan bahan bacaan atau literatur yang edukatif dan menghibur, serta tidak mengandung unsur pornografi dan SARA.

\subsection{Hoax}

Hoax merupakan usaha membohongi pembaca atau pendengarnya untuk mempercayai informasi tertentu, meskipun pembuat berita mengetahui bahwa berita tersebut bohong. Penyebaran berita hoax dilakukan untuk membuat dan menggiring pendapat publik, membentuk persepsi, untuk having-fun atau bahan lelucon, iseng, menjatuhkan pesaing (black campaign), promosi dengan penipuan, ataupun ajakan untuk berbuat amalan baik tanpa dalil yang jelas di dalamnya (Rahadi, 2017). Informasi hoax mempunyai dampak negatif dikarenakan dapat menyebabkan ketakutan, apabila informasi tersebut telah diterima atau dibaca oleh publik, maka dapat mempengaruhi emosi, perasaan, dan perilaku seseorang/kelompok.

Informasi hoax terdiri dari tujuh jenis, yaitu: (1) berita bohong (fake news), bertujuan untuk memalsukan atau memasukkan ketidakbenaran dalam suatu berita; (2) tautan jebakan (clickbait), bertujuan untuk menarik orang masuk ke situs lainnya, biasanya sesuai fakta namun judulnya berlebihan atau memasang gambar yang menarik; (3) bias konfirmasi, kecenderungan dalam menginterpretasikan kejadian yang baru terjadi sebaik bukti dari kepercayaan yang sudah ada; (4) informasi yang tidak akurat, informasi yang dibuat dengan tujuan untuk menipu; (5) satire, sebuah tulisan yang menggunakan humor, ironi, hal yang dibesar-besarkan untuk mengomentari kejadian yang sedang beredar di masyarakat; (6) pascakebenaran (post-truth), kejadian di mana emosi lebih berperan daripada fakta untuk membentuk opini publik; (7) propaganda, aktivitas menyebarkan informasi, fakta, argumen, gosip, setengah-kebenaran, atau kebohongan untuk mempengaruhi opini publik (Rahadi, 2017).

Terkait dengan hukum, hoax merupakan tindak pidana sehingga pelaku hoax dapat dikenakan sanksi yakni melanggar UU Informasi dan Traksaksi Elektronik. UU tersebut khususnya ayat 1 pasal 28 , menyebutkan bahwa "setiap orang dengan sengaja dan tanpa hak menyebarkan berita bohong dan menyesatkan yang mengakibatkan kerugian konsumen dalam transaksi elektronik; dan ayat 2 menyebutkan bahwa "ketentuan larangan kepada setiap orang untuk menyebarkan informasi yang menimbulkan kebencian/permusuhan". Sanksi bagi pembuat informasi hoax dalam pasal 45 ayat 2 yaitu pidana penjara paling lama 6 bulan dan/atau denda paling banyak Rp 1.000.000.000,- (satu miliar rupiah). 


\subsection{Minat Baca}

Minat baca secara harfiah terdiri dari dua kata, yaitu minat dan baca. Menurut KBBI, minat artinya kecenderungan hati yang tinggi terhadap sesuatu; gairah; keinginan, sedangkan membaca artinya melihat serta memahami isi dari apa yang tertulis. Minat adalah kecenderungan afektif (perasaan, emosi) seseorang untuk membentuk aktivitas (Khofiah, 2015). Menurut Tampubolon dalam Arisma (2012), membaca merupakan satu dari empat kemampuan bahasa pokok, dan satu bagian atau komponen dari komunikasi tulisan. Minat baca dapat diartikan sebagai keinginan atau gairah untuk melakukan kegiatan membaca. Dengan minat baca yang tinggi, seseorang akan memperoleh manfaat dari kegiatan membaca mempengaruhi perilaku seseorang dalam bertindak dan berpikir. Membaca berfungsi menyerap informasi dari teks yang dibacanya. Membaca memberikan pengetahuan dan pencerahan bagi pembacanya. (Kasiyun, 2005).

Menurut Gray \& Rogers dalam Sugiarti (2012), membaca memiliki manfaat: (1) meningkatkan ilmu pengetahuan, daya nalarnya berkembang dan memiliki wawasan yang luas; (2) memiliki perbendaharaan kata dan imajinasi dan kemampuan pikir yang luas; (3) memiliki kemampuan praktis dalam kehidupan sehari-hari; (4) meningkatkan minat terhadap suatu bidang/menimbulkan kreativitas

\section{METODE}

Penelitian ini merupakan penelitian kualitatif dengan menggunakan metode pengumpulan data observasi parsipatif dan dokumentasi. Observasi parsipatif adalah observasi yang melibatkan peneliti dalam kegiatan sehari-hari orang yang sedang diamati atau yang digunakan sebagai sumber data penelitian (Sugiyono, 2008).

\section{HASIL DAN PEMBAHASAN}

\subsection{Sekilas tentang Perpustakaan UNS}

Perkembangan Perpustakaan UNS tidak terlepas dari sejarah perkembangan UNS. Berdasarkan SK Rektor UNS tanggal 14 Agustus 1980, No.134/PT.40/C/1980 didirikanlah Unit Pelaksana Teknis (UPT). Tugas yang diemban oleh Perpustakaan UNS merujuk pada Permendikbud No.82 tahun 2010, pasal 102 tentang SOTK UNS, yaitu memberikan layanan kepustakaan. Dalam menjalankan fungsinya, Kepala Perpustakaan UNS menetapkan misi perpustakaan menjadi pusat sumber belajar, penelitian, pengabdian kepada masyarakat, dan layanan informasi yang prima dan unggul di tingkat dunia pada tahun 2030. Adapun visi perpustakaan adalah menjadi mitra seluruh sivitas akademika dan pemustaka sebagai pusat sumber belajar mandiri berbasis pustaka, pusat penelitian mandiri dan kolegial berbasis pustaka, menjadi mitra layanan prima bagi seluruh sivitas akademika dan pemustaka secara mandiri dan kolegial yang mendukung implementasi tri dharma perguruan tinggi, dan menjadi pusat media publikasi dan pusat koleksi berbagai keunggulan ilmiah bagi seluruh civitas akademika dan pemustaka di tingkat nasional, asia tenggara, dan dunia.

\subsection{Upaya Peningkatkan Minat Baca}

Ada berbagai upaya Perpustakaan UNS dalam rangka peningkatan dan pengembangan minat baca masyarakat diantaranya sebagai berikut.

1) Kegiatan talk show 
Talk show untuk mahasiswa maupun siswa sebagai upaya perpustakaan mengembangkan dan menumbuhkan budaya membaca dan menulis. Contoh kegiatannya yaitu:

- Talk Show Jurnalistik, bekerjasama KPw Bank Indonesia Solo, yang diwakili oleh Komunitas Generasi Baru Indonesia (GenBI) Solo, dengan tema "How to be a Citizen Journalist.". Tujuan kegiatan ini adalah untuk meningkatkan dan mengapresiasi mahasiswa dan pelajar untuk terus mengembangkan potensinya dalam hal membaca dan menulis.

- Kids Talk dengan tema "Spreading You Ideas", bekerjasama dengan Lazuardi KamilaGIS, dengan tema "Spreading You Ideas". Kegiatan ini diikuti oleh siswa dari SD dan SMP Lazuardi Kamila (pada 2 Maret 2018). Kegiatan ini sebagai wadah bagi siswa untuk mengeksplorasi ide, pemikiran, atau opininya tentang sesuatu yang sedang diminatinya, seperti social media, culture, maupun passion. Keterampilan membaca dan menulis harus dipraktikkan dan dilatih secara terus menerus, setelah tumbuh budaya membaca dan menulis pada ranah keluarga, ajaklah anak-anak untuk membiasakan diri menuangkan ide gagasannya secara lisan dan tulis.

2) Lomba resensi buku dan menulis

Kegiatan menulis tidak terlepas dari aktivitas membaca. Kegiatan ini diselenggarakan bersamaan dengan event resmi seperti hari buku. Peserta lomba terdiri dari mahasiswa dan pelajar (SMA Sederajat) se-Solo Raya.

3) Menerima kunjungan dari lembaga lain

Kegiatan ini berupa penerimaan kunjungan dari berbagai sekolah, mulai dari tingkat sekolah dasar (SD), sekolah menengah pertama (SMP), sekolah menengah umum (SMU), hingga perguruan tinggi lainnya. Peserta kunjungan diantaranya kunjungan dari siswa yang tergabung dalam Club Pecinta Buku (CPB), Madrasah Aliyah Negeri (MAN) 1 Sragen (pada 19 Februari 2018).

4) Kampanye budaya literasi

Tujuan kegiatan ini adalah untuk memperkenalkan perpustakaan kepada masyarakat umum, khususnya kepada masyarakat Kota Solo agar membudayakan membaca dan menulis. Kegiatan ini sebagai upaya memperkenalkan perpustakaan untuk memunculkan keinginan seseorang untuk terus membaca dan menggali ilmu pengetahuan.

5) Workshop dan seminar

Tujuan kegiatan ini adalah untuk memperkuat budaya membaca dan menulis. Contoh kegiatan Workshop "Bangga Berbahasa Indonesia untuk Menguatkan Budaya Literasi Dengan Membaca dan Menulis" (pada 27 Agustus 2017) dan Workshop "Strategi Menelusur Informasi melalui Google dan E-Resource Library" (pada 30 Agustus 2018), pesertanya berasal dari mahasiswa, staf, dan dosen UNS.

6) Pelatihan literasi informasi

Materi pelatihan mencakup kegiatan mengakses sumber-sumber informasi elektronik (ejournal, e-book, dan informasi digital library), pengenalan software plagiarism checker dengan Turnitin, literasi menemukan dan submit jurnal international. 
7) Pameran buku

Pameran buku merupakan agenda rutin tahunan Perpustakaan UNS. Melalui kegiatan pameran diharapkan dapat memberikan kesempatan kepada masyarakat untuk menambah khasanah pustaka sekaligus sebagai ajang sosialisasi perpustakaan.

8) Penyediaan aneka ragam koleksi

Perpustakaan UNS menyediakan koleksi buku dan jurnal, baik dalam bentuk cetak maupun elektronik. Bidang ilmu koleksi cetak yang tersedia di perpustakaan mencakup bidang umum dan filsafat, psikologi, agama, sosial, ilmu murni, ilmu terapan, teknologi, kesusastraan, biografi dan sejarah. Sedangkan koleksi elektronik dapat diakses melalui website https://library.uns.ac.id. Pengembangan koleksi buku berasal dari pembelian, hibah/sumbangan.

9) Mempromosikan berbagai koleksi perpustakaan

Sarana promosi perpustakaan mencakup penyebaran brosur, informasi pada website dan media sosial perpustakaan UNS, sepertitwitter@UNSLib, Instagram@unslibrary UNS, Youtube di chanel UNS library, dan facebook@UNSLibrary.

10)Implementasi layanan prima kepada pemustaka

"Layanan Prima dan Unggul" menjadi tagline Perpustakaan UNS untuk melayani pemustaka. Untuk mewujudkan tagline tersebut, Kepala Perpustakaan UNS telah menerapkan layanan 5S yaitu Senyum, Sapa, Salam, Sopan, dan Santun. Konsep layanan 5S tersebut diharapkan pemustaka mendapatkan senyuman ramah dari pustakawan. Jika pemustaka mendapatkan layanan terbaik dari pustakawan, mereka akan senang untuk datang dan memanfaatkan kembali perpustakaan untuk belajar, membaca, dan berdiskusi.

11) Peningkatan sarana prasarana perpustakaan

Perpustakaan UNS menyediakan ruang baca bagi pemustaka, dilengkapi dengan pendingin ruangan, jaringan listrik, wifi, ruang SAT (ruang kompuer dan akses internet). Berbagai fasilitas tersebut ditujukan untuk memberikan dukungan dan kenyamanan pemustaka dalam melakukan aktivitas belajar, membaca, dan menulis.

Berbagai informasi kegiatan di atas dapat dilihat di website Perpustakaan UNS dengan judul artikel atau berita sebagai berikut.

- Kuatkan Budaya Literasi, Perpustakaan UNS Selenggarakan Workshop Penulisan, di https://ibrary.uns.ac.id/category/events/page/3/.

- Lomba Resensi dan Menulis Artikel Ilmiah Tahun 2018, di https://ibrary.uns.ac.id/6884-2/.

- Pelatihan Literasi Informasi UPT Perpustakaan UNS, di https://library.uns.ac.id/information-literacy-training/.

- Perpustakaan UNS Mengkampanyekan Budaya Literasi di Solo Paragon Mall, di https://library.uns.ac.id/perpustakaan-uns-mengkampanyekan-budaya-literasi-di-soloparagon-mall/.

- Perpustakaan UNS Terima Kunjungan Mahasiswa Prodi Pendidikan Bahasa Indonesia FKIP Universitas Jember, di https://library.uns.ac.id/perpustakaan-uns-terimakunjungan-mahasiswa-prodi-pendidikan-bahasa-indonesia-fkip-universitas-jember/. 
- Workshop Strategi Menelusur Informasi melalui Google dan E-Resource Library, di https://ibrary.uns.ac.id/category/events/page/3/.

\subsection{Mengantisipasi Informasi Hoax}

Perpustakaaan UNS memiliki berbagai koleksi, baik koleksi tercetak maupun elektronik. Koleksi yang dimiliki dapat dijadikan sebagai sumber informasi untuk mengantisipasi informasi hoax. Hal tersebut dapat dilakukan jika disertai dengan kemauan atau minat baca masyarakat. Perpustakaan UNS juga mengoptimalkan pemanfaatan koleksi dan layanannya untuk meningkatkan minat baca masyarakat. Diharapkan masyarakat memiliki pengetahuan yang tinggi agar tidak akan mudah terpengaruhi oleh informasi hoax. Upaya peningkatan minat baca yang dilakukan oleh Perpustakaan UNS ini erat kaitannya dengan tingginya pengunjung perpustakaan.

\section{KESIMPULAN}

Saat ini, internet telah menjadi kebutuhan utama masyarakat, dan penetrasi penggunaan internet didominasi oleh media sosial. Salah satu efek negatif penggunaan media sosial adalah maraknya informasi hoax. Hoax termasuk tindakan kejahatan yang sangat membahayakan masyarakat sehingga perlu adanya sanksi dan upaya nyata dalam pencegahannya. Koleksi yang dimiliki perpustakaan dapat menjadi informasi terpercaya atau dapat dipertanggung jawabkan. Perpustakaan sebagai penyedia informasi harus mengoptimalkan perannya dalam meningkatkan minat baca masyarakat agar mereka tidak mudah menerima informasi hoax. Berbagai upaya dan strategi Perpustakaan UNS, seperti melalui kegiatan talk show, pameran buku, workshop dan seminar kepenulisan, literasi informasi, menerima kunjungan siswa dan mahasiswa, menerapkan layanan prima dan unggul, penyediaan aneka macam koleksi, promosi perpustakaan dan peningkatan sarana prasarana perpustakaan UNS, diharapkan dapat meningkatkan minat baca masyarakat. 


\section{DAFTAR PUSTAKA}

Arisma, Olynda Ade, 2012 Peningkatan Minat dan Kemampuan Membaca Melalui Penerapan Program Jam Baca Sekolah di Kelas VII SMP Negeri Puri. Malang: Fakultas Sastra Universitas Negeri Malang.

Asosiasi Pengguna Jasa Internet Indonesia. 2017. Infografis Hasil Survey 2017. Di www.technopreneur.com (akses 1 Maret 2018).

Augusta, Ryan. 2017. Bahaya Berita Hoax, Publik Dirugikan. Di http://bangka.tribunnews.com/2017/10/26/bahaya-berita-hoax-publik-dirugikan (akses 28 Maret 2018).

Fuad, Anis, Ida Fajar Priyanto, \& Donni Zuliyanto. 2017. Pustakawan Berperan dalam Menyajikan Informasi Sehat. Makalah Seminar "Perpustakaan Sebagai Gerbang Informasi Sehat" Yogyakarta: Universitas Gadjah Mada.

Kasiyun, Suharmono. 2005. Upaya Meningkatkan Minat Baca sebagai Sarana untuk Mencerdaskan Bangsa. Jurnal Pena Indonesia, Vol.1,No.1.

Khofiah, Siti. 2014. Hubungan Minat Baca dengan Kemampuan Membaca Pemahaman Siswa Kelas Tinggi SDN 1 Karangsari Kecamatan Pengasih Kabupaten Kulon Progo Tahun Ajaran 2014/ 2015 Yogyakarta: Universitas Negeri Yogyakarta.

Nashihuddin, Wahid. 2017. Pustakawan, Penangkal Informasi Hoax di Masyarakat. Jakarta: Pusat Dokumentasi dan Informasi Ilmiah https://www.researchgate.net/publication/313859853 (akses 3 April 2018).

Pamuntjak-Sjahrial, Rusina. 2000. Pedoman Penyelenggaraan Perpustakaan. Jakarta: Penerbit Djambatan.

Putri, Wilga Secsio Ratsja, Nurwati, R., Nunung, Budiarti S, \& Meilanny. 2016. Pengaruh Media Sosial terhadap Perilaku Remaja. PROSIDING KS: RISET \& PKM, Vol.3, No.1.

Rahadi, Dedi Rianto. 2017. "Perilaku Pengguna dan Informasi Hoax di Media Sosial. Jurnal Manajemen dan Kewirausahaan, Vol.5, No.1.

Republik Indonesia. 2007. Undang-Undang Nomor 43 Tahun 2007 tentang Perpustakaan. Jakarta: Kementerian Hukum dan Hak Asasi Manusia.

Republik Indonesia. 2008. Undang-Undang Nomor 11 Tahun 2008 tentang Transaksi Elektronik. Jakarta: Kementerian Hukum dan Hak Asasi manusia.

Republik Indonesia. 2008. Undang-Undang Nomor 19 Tahun 2016 tentang Informasi dan Traksaksi Elektronik. Jakarta: Kementerian Hukum dan Hak asasi Manusia.

Republik Indonesia. 2014. Permendikbud Nomor 82 Tahun 2014 tentang Sistem Organisasi dan Tata Kerja Universitas Sebelas Maret. Jakarta: Kemeterian Pendidikan dan Kebudayaan.

Respati, Sheila. 2017. Mengapa Banyak Orang Mudah Percaya Berita Hoax? Di https://nasional.kompas.com/read/2017/01/23/18181951/mengapa.banyak.orang.mudah.perc aya.berita.hoax...(akses 28 Maret 2018).

Rizki, Juni Wati Sri. 2013. Optimalisasi Fungsi Perpustakaan Perguruan Tinggi Melalui Peran Pustakawan. Al-Kuttab: Jurnal Perpustakaan dan Informasi, Vol.1,No.2.

Siregar, A. Ridwan. 2004. Perpustakaan Energi Pembangunan Bangsa. Medan: Universitas Sumatera Utara.

Sugiarti, Uci. 2012. Pentingnya Pembinaan Kegiatan Membaca Sebagai Implikasi Pembelajaran Bahasa Indonesia. Di jurnal.unimed.ac.id/2012/index.php/basastra/article/.../201/80 (akses 28 Maret 2018).

Sugiyono. 2008. Memahami penelitian kualitatif. Bandung: Alfabeta. 
Suyono, Riska Amaliah, Dewi Ariani, \& Ariva Luciandika. 2015. Cerdas Menulis Karya Ilmiah. Penerbit Gunung Samudera [Grup Penerbit PT. Book Mart Indonesia].

Triatma, Ilham Nur. 2016. Minat Baca pada Siswa Kelas VI Sekolah Dasar Negeri Delegan 2 Prambanan Sleman Yogyakarta. E-Jurnal Prodi Teknologi Pendidikan, Vol.V,No.6. 